\title{
The Research of Customers Satisfaction and Public Policy \& Marketing Design in Special Interest Tourism-Macao Culinary Tourism
}

\author{
Xin Wang ${ }^{1} \&$ Ting Meng ${ }^{2}$ \\ ${ }^{1}$ Faculty of International Tourism and Management, City University of Macau, Macao \\ ${ }^{2}$ School of Business, Macau University of Science and Technology, Macao \\ Correspondence: Xin Wang, Faculty of International Tourism and Management, City University of Macau, \\ Macao. E-mail: xwang@cityu.edu.mo
}

Received: October 20, 2015

doi:10.5539/ijbm.v11n1p124

\begin{abstract}
Start from the development of domestic and foreign fine good, the basic principles and practice from government policy program and formulation, as well as interviews with experts and surveys for the tourists based on physical truth of the Macao culinary tourism development, we did research for the customers satisfaction of Macao culinary tourists and designed strategies and concrete measures of the public policy \& marketing. The paper will present policy action suggestions via measure the relationship of government public marketing and customers satisfaction of food tourists through factor analysis from multiple regression analysis.
\end{abstract}

The research believes regional tourism as a quasi-public product, public department plays significant role in its marketing practice. To design the public marketing strategies based on integration of government organizations, tourism industry and civil society groups will offer more comprehensive marketing capacity of private organizations, citizens and other stakeholders. It will very helpful to promote the overall value of Macao tourism, boost regional welfare and sustainable development in tourism industry.

Keywords: special interest tourism, customers satisfaction, public policy \& marketing, Macao culinary tourism

\section{Introduction}

Gambling industry is a pillar of the Macao economy and the symbol of Macao in the world, which become the most attractive factor for tourists. China's Twelfth Five-year Plan clearly expressed: 'Support Macao to build the world class tourism and leisure center, promotes economic diversification.' Over the last decade, Macao created a mythology about unbelievable increase in gaming revenues. From 447 hundred million Hong Kong dollar in 2005 increased sharply to 3,500 hundred million Hong Kong dollar in 2013, growth of nearly 7 times within 8 years and the compound annual rate of growth was $29.3 \%$. Meanwhile, the number of the gaming tables significantly increased. From 1,388 tables in 2005 increased to 5,750 tables in the year-end 2013, the compound annual rate of growth was $19.3 \%$. After the high speed growing, there has been the first time backward going by year in Macao gambling revenues since 2001 gambling license opened, annual declined 2.6\%. Revenues in gambling industry remains in recession from the beginning of this year. Until May of 2015, the gambling monthly revenue decreased lasting 12 month in a year. The whole industry revenue in reduced circumstances (Chiefgroup, 2015)

Currently, Macao government try to fade out the wager city image by using variety of measures, and to reduce the negative effects of overly dependent upon gambling industry by build the world class tourism and leisure center. Variety measures which including emphasize on cultural heritage to attract people travel to Macao and make it as a major image of Macao tourism. In addition, Macao government also promotes the diversified development of business conferences, exhibitions and recreational culture tourisms. However, the region of Macao is small and meagre resources. Sustainable development strategy is extremely important and Macao government should fully explore, develop and utilize the existing characteristic resources. Exploiting the catering culture is becoming the significant move to develop tourism economy in many countries. Macao is a place of integration of Chinese and Western culture since ancient times, which including dietary culture. Chinese and western dietetic culture melts into another, except traditional Chinese Cuisine Macao also have Western Cuisine, 
Southeast Asia Cuisine, Japanese Cuisine and, combining Chinese and Western dietetic cultures and featuring a unique local characteristics Macanese Portugal Cuisine. Macanese Gastronomy was inscribed on the Macao Intangible Cultural Heritage List in 2012. Consequently, fully utilize the dietetic culture resources to combine delicacy with tourism will diversify the tourism products. Also, it will increase attractiveness of Macao tourism, publicize Macao dietary cultural heritage and enrich Macao tourism image to boosting sustainable development of tourism industry.

What is Special Interest Tourism? According to Read, 'special interest travel is travel for people who are going somewhere because they have a particular interest that can be pursued in a particular region or at a particular destination. It is the hub around which the total travel experience is planned and developed' (Read, 1980). Meg Houghton (2008) defined delicacy tourists broadly, he pointed out that the people who willing to participate in delicacy event or look for local cuisines will consider as delicacy tourists even they are not only come for delicacies. The promotion for Culinary Tourism will attract their attention.

Many researchers regard customer satisfaction and repurchase as the key points of successful factors. American scholars Sylvia Smith and Carol Costello (2008) based on Saleh and Ryan's (1993) research about decision-making factors to attract tourists participate in the delicacy event, took 'The World Barbecue Cook-off' which held in Memphis, Tennessee in 2006 as object to research customer satisfaction of culinary tourism. Researchers selected 27 factors composed a factor list which affect customer satisfaction from 52 pull factors through expertise interview and Delphi method. Sylvia Smith and Carol Costello provided very valuable guidance and reference for this research, and the evaluation factors used in this research about Macao Culinary Tourism customers satisfaction also from them.

Victor Middleton (2001) indicated that, destination marketing has two levels: the first level is focus on the whole destination and its tourism products. This is the key point of the work by local National Tourism Organization. The second level covering activities to promote individual products by business organizations. Thus it can be seen that different as traditional business marketing, tourism destination marketing including promotion for the whole destination and tourism products activities. According to marketing guru Philip Kotler's divisions of social organizations to enterprise, government and non-profit organizations, public organizations should including government and non-profit organizations. From comparation of public marketing principles, government marketing and non-profit marketing principles we can see that because of government marketing and non-profit marketing only refer to some main parts of the public product marketing, thus the extensive principles of public marketing is broader than government marketing and non-profit organization marketing. Meanwhile, from the connotational aspect, the supply of public marketing and public product, public governance etc have necessary connection with each other. However, the government marketing, non-profit organizations cannot reveal the essential content which related to the supply of public product and governance. Therefore, the connotation of the principles of pubic marketing also profounder than government marketing and non-profit organization marketing. Xiong Yuanbin (2008) defined public marketing as, public marketing is marketing activities for the public and quasi-public product which led by government, non-profit organizations and public organizations, and jointly with enterprise private sector and individuals and so on. The purpose is to enhance the better understanding of public and quasi-public product, intensify people's identification of public and quasi-public product image to achieve the public interest. In this concept, the research think public organizations is an organizational entity which work for the public purpose, provide communal article and service established accordance with legal procedures.

"Policy design extends to either the means or mechanisms through which policy goals are given effect, and to the goals themselves, since goal articulation inevitably involves considerations of feasibility, or what is practical or possible to achieve in given conjunctures or circumstances given the means at hand." (Giliberto Capano, 2013)

This research established three objectives based on the literatures which mentioned above:

1) Measure the gap between actual performance and significance of various influencing factors in culinary tourism to obtain the entirety satisfaction evaluation of Macao Culinary Tourism;

2) Forecast the influence of public marketing policy and measures to enhancing the customer satisfaction of Macao Culinary Tourism;

3) Ascertain the relationship between government public marketing and customer satisfaction of culinary tourism, underlie for government policy design and offer suggestions for government operations.cul 


\section{Research Method and Data}

\subsection{Research Constitution}

Three parts in questionnaire survey: The first part is basic information of interviewees, which including origin of interviewees, gender, education level, occupation, marital status and so on. The second part is the survey about satisfaction of details in different delicacy activities. Interviewees will rate on a scale of 5 to 1: 5 mark represent 'strongly agree', 1 mark stand for 'strongly disagree', et cetera. The third part is gauge of public policy \& marketing support in culinary tourism. Select top three score suggestions for public and policy marketing, strategies and management of Macao culinary tourism develop by expert panel into the questionnaire, list these suggestions to interviewees and ask them rate on a scale of 5 to $1: 5$ mark represent 'strongly agree', 1 mark stand for 'strongly disagree', et cetera.

The combination of Delphi method and questionnaire for tourists will be used in this research to collecting datas. First of all, get suggestions and strategies of government formulation in tourism public marketing policies in Macao culinary tourism through synthetically data collection and analysis from two rounds Delphi experts interview results. Then, design the questionnaires via refine those suggestions and strategies and to examining the feasibility and Support Rating through this questionnaires result from tourists.

\subsection{Data Collection}

After organized experts panel, this research used Delphi Method did two rounds experts interview on December 2014 to January 2015 and January to February 2015.

There are five delicacies rendezvous in Macao: (1) the tourist area comprising Avenida de Almeida Ribeiro, Rua da Felicidade and Largo do Senado Square; (2) the casino congregation area in Avenida da Amizade; (3) The Venetian Macao-Resort-Hotel as the center along with the Cotai Strip area; (4) Rua do Cunha and Rua de Regedor tourist area in Taipa; (5) special food souvenir shops area in Istmo de Ferreira do Amaral. The survey will take Nonrandom Sampling Method to conduct the questionnaire to Macao culinary tourists in these five delicacies rendezvous. The survey was conducted in March to April, 2015. Questionnaires were distributed and took back on the spot. Out of 502 questionnaires distributed, $475(95 \%)$ were retuned. The reliability analysis result by SPSS is Cronbach's Alpha $=0.8662$ which indicate the design of questionnaires is reliable.

\section{Findings}

\subsection{Descriptive Statistical Analysis of Respondents' Information}

In this survey, there were 256 females (53.9\%) and 219 males (46.1). Overall, it is inconspicuous on gender difference that tourists with the view to delicacy to travel to Macao. Most of the respondents were young people between 18 and 35 years (64\%) old. As for the respondents' occupation, most of them were students and full time staff which accounted for $65.2 \%$. A total of $42.3 \%$ and $25.1 \%$ of respondents had obtained a college or university degree and high school diploma. From the origins of respondents, $62.3 \%$ from mainland China and $29.7 \%$ from HongKong.

\subsection{Satisfaction Analysis of Macao Culinary Tourism}

The first research purpose of this paper is get the overall satisfaction level of Macao Culinary Tourism through measure the difference between various factors' actual performance and significance during the trip. Table 1 is the results of statistical analysis of tourisms' opinion about various composing elements' actual performance and significance of Macao Culinary Tourism. Significance and performance are two independent variables, and 20 elements in the questionnaires represent dependent variables. After acquired the mean difference of significance and performance, to testing the individual effects of each variable through ANOVA. 
Table 1. The scoring sheet of culinary tourism elements' significance and performance by tourists

\begin{tabular}{|c|c|c|c|c|c|}
\hline Elements & Significance & Performance & Mean Difference & Variance Ratio & Conspicuousness \\
\hline 2.18 Clear Labeling of Food Ingredients & 3.3020 & 3.2409 & 0.0611 & 0.714 & 0.070 \\
\hline 2.19 The Embodiment of Catering Culture & 3.7769 & 3.5822 & 0.1947 & $29.236 * * *$ & 0.000 \\
\hline 2.20 Guide/Map/Activity Introduction & 4.0010 & 3.1712 & 0.8289 & $40.433 * * *$ & 0.000 \\
\hline 2.21 Price of Food and Drinks & 3.7812 & 3.2881 & 0.4931 & $10.189^{*}$ & 0.020 \\
\hline 2.22 Related Activities or Exhibitions & 3.6614 & 3.1800 & 0.4814 & $2.785 * * *$ & 0.001 \\
\hline 2.23 Venues Cleanliness & 3.9618 & 3.5352 & 0.4266 & $18.295 * * *$ & 0.000 \\
\hline 2.24 Convenience of Purchase & 3.9746 & 3.3659 & 0.6087 & $9.943 * * *$ & 0.000 \\
\hline 2.25 Transportation Convenience & 3.8458 & 3.3659 & 0.4799 & $18.450 * * *$ & 0.000 \\
\hline 2.26 Cultural Attraction & 3.7047 & 3.3571 & 0.3476 & $5.802 *$ & 0.033 \\
\hline 2.27 Food Safety & 4.0196 & 3.7949 & 0.2247 & $5.777^{*}$ & 0.015 \\
\hline 2.28 Free Tasting & 3.4025 & 3.3794 & 0.031 & 0.514 & 0.092 \\
\hline 2.29 Environment Attractiveness & 3.7896 & 3.4384 & 0.3904 & $8.432 *$ & 0.010 \\
\hline 2.30 Taste & 3.9286 & 3.5117 & 0.4169 & $16.358 * * *$ & 0.000 \\
\hline 2.31 Music/Entertainment & 3.5143 & 3.5000 & 0.0143 & 0.592 & 0.250 \\
\hline 2.32 Number of Popular Local Restaurant & 3.8288 & 3.5117 & 0.3171 & $10.03 * * *$ & 0.000 \\
\hline 2.33 Friendly Service & 3.9658 & 3.1468 & 0.8190 & $7.452 * * *$ & 0.000 \\
\hline 2.34 Knowledgeable Service & 3.4746 & 3.3451 & 0.1331 & 46.172 & 0.000 \\
\hline 2.35 Celebrity Chef Cooking Performance & 3.3288 & 3.1947 & 0.1341 & 31.347 & 0.001 \\
\hline 2.36 Incidental Shopping Environment & 3.6640 & 3.2740 & 0.3900 & 35.038 & 0.000 \\
\hline 2.37 Local Growth and Production of the Food & 3.3611 & 3.3493 & 0.0188 & 30.864 & 0.001 \\
\hline
\end{tabular}

\subsubsection{Significance Analysis of Culinary Tourism Elements}

In 20 elements, respondents thought Food Safety, Guide/Map/Activity Introduction, Convenience of Purchase, Friendly Service, Venues Cleanliness, and Taste were the most important 6 elements in Culinary Tourism. The requirements for Clear Labeling of Food Ingredients, Celebrity Chef Cooking Performance, Local Growth and Production of the Food and Free Tasting are relatively low. In this survey, more than $70 \%$ of respondents considered Taste, Friendly Service, Food Safety, Venues Cleanliness, Guide/Map/Activity Introduction and Convenience of Purchase were the most important elements.

\subsubsection{Performance Analysis of Culinary Tourism Elements}

In 20 elements, respondents thought Food Safety, The Embodiment of Catering Culture, Venues Cleanliness, Taste, Number of Popular Local Restaurant and Music/Entertainment scored the highest. The mean of these 6 elements were $3.5000 \sim 3.7949$, between 'common' and 'satisfaction', and trends to satisfaction level. On the other hand, the score of 12 elements which are Clear Labeling of Food Ingredients, Guide/Map/Activity Introduction, Price of Food and Drinks, Related Activities or Exhibitions, Convenience of Purchase, Transportation Convenience, Cultural Attraction, Friendly Service, Knowledgeable Service, Celebrity Chef Cooking Performance, Incidental Shopping Environment and Local Growth and Production of the Food scored by respondents lower than the mean of overall satisfaction level (3.3764). The mean of these scores were 3.1468 $\sim 3.3659$, between 'common' and 'satisfaction', close to common level. Within it, more than $20 \%$ of respondents 
deemed 'dissatisfaction' and 'strongly dissatisfaction' on the 3 elements: Friendly Service (24.2\%), Guide/Map/Activity Introduction (21.4\%) and Related Activities or Exhibitions (21\%). Thus it can be seen, these elements have a lot of exsisting problems, and need to further enhancement and improve.

\subsubsection{Difference Analysis of Significance and Performance in Culinary Tourism Elements}

Form the scoring sheet of culinary tourism elements' significance and performance by tourists (Table 1) can tell that, the 5 elements with the great difference of significance and performance are Guide/Map/Activity Introduction (Mean Difference: 0.8289), Friendly Service (Mean Difference: 0.8190), Convenience of Purchase (Mean Difference: 0.6087), Price of Food and Drinks (Mean Difference: 0.4931), Related Activities or Exhibitions (Mean Difference: 0.4931). These 5 elements are the major factors influence the tourists's overall satisfaction about Macao Culinary Tourism. The reasons as following:

\section{1) Guide/Map/Activity Introduction}

According to the author's spot observation, Macao dietary culture as a name card of Macao did not played a constructive role. The external publicity and promotion method is too unitary. Many tourists come to Macao looking for the specialty food with a gourmet book published by other place. There is no Macao local gourmet map, no leaflets, tourists cannot received any information about gourmet activity, even many tourists didn't know Macao Food Festival was holding on.

\section{2) Friendly Service}

Respondents reflected that the service quality of Macao Culinary Tourism practitioners were uneven. Some service staff with gracious manner, some sales were well trained in courteous and attentive service to every guest, and also enthusiastic accosted free tasting to promote their food. However, there were also some of staff impolite especially in peak hours. Also, the service of star hotels with well management standards were much better than the private owner's restaurant on the street.

\section{3) Convenience of Purchase}

Many of the respondents told their own experience that when they travelled to Macao during new year holidays, many of restaurants were closed except the restaurants inside of hotels and casinos. The reason is the labour shortage during holidays and according to the law of Macao, people will get 3 times salary to working on the holidays. Therefore, most of the owners will close their restaurants during public holidays. Respondents said it was very difficult to find the place to eat except hotels during those days.

\section{4) Price of food and drinks}

Recent years in Macao, inflation continually accelerating and dinning price are increasing year by year. Especially, the restaurants in tourist area under great pressure of rent increases thus have to rise the food price frequently. It is quite common that twenty-something a cup of drink, and thirty to forty for a set meal. For gourmet traveller, they'd like to tasting all the specialty food for the reason to tasting the variety of delicacies one time. Consequently, the total cost of gourmet traveller will increase significantly.

\section{5) Related Activities or Exhibitions}

Although there is 'Macao Food Festival' annually, and different exhibitions like 'Guang Dong and Macao Branded Products Fair' and 'Macao Import Commodities Expo' were holding in Venetian and Fisherman's Wharf, food related exhibitions did not formed the scale yet and the promotion about Macao specialty less prominent. Macao government should support specialty cuisine relative activities, such as 'Myanmar Food Festival' in Rotunda de Carlos da Maia, 'Thai Food Festival' in Av. do Conselheiro Ferreira de Almeida and 'Portuguese Wine and Food Festival' in Freguesia de Sao Lourenco to form the scale.

\subsection{The Influence of Public Policy and Marketing on Improving the Overall Satisfaction of Macao Culinary Tourism}

The second objective of this research is predict the influence of public policy and marketing measures on improving the overall satisfaction of Macao Culinary Tourism. Questions in questionnaire came from the experts interview result. To get the final score of different suggestions and strategies of government formulation in tourism public marketing policies in Macao culinary tourism through synthetical data collection and analysis from two rounds Delphi experts interview results. Then, these suggestions and strategies were listed by average score, and three highest score suggestions in each section formed questionnaire in part three. Subsequently, the suggestions and strategies have been provided to Macao culinary tourists and evaluated by support rating from them. In the survey of culinary tourists, measure the public policy and marketing support of culinary tourism with 15 questions. 
To do the KMO and Bartlett test before factor analysis. The results are shown in Table 2: KMO value is 0.96, index statistics more than 0.8 , presents the stander of nature is 'good' which means there are common factors among the variables and fit for factor analysis. Furthermore, the $\mathrm{X}^{2}$ value of Bartlett's sphericity test is 2798.457, (degree of freedom is 171) reaches 0.05 level of significance, and could reject the null hypothesis. The significance probability $\mathrm{p}=0.001<0.05$ in Table 2 , could reject the null hypothesis and accept the hypothesis of net correlation matrix is element matrix, which means there are common factors in overall correlation matrixes which are suitable for the factors analysis.

Table 2. Kmo and Bartlett test

\begin{tabular}{lll}
\hline Kaiser-Meyer-Olkin & $\mathbf{0 . 9 6}$ \\
\hline Bartlett Sphericity Test & Approximate Chi square distribution & 2798.457 \\
& Degree of Freedom & 171 \\
& Significance & 0.001 \\
\hline
\end{tabular}

Factor analysis results are shown in Table 3 by using Varimax Rotation Principal Component Analysis. There are three factors with eigenvalues greater than 1.0, as a final common factor, the total variance can be explained by three common factors for $62.22 \%$, and more than $50 \%$ illustrates the condition of variable is 'ideal'. Cronbach's Alpha $=0.96$ in the table which indicates the internal consistency is very reliable. Three common factors are: (1) Policy (eigenvalue $=13.94$, explained variance $=25.77 \%, \alpha=0.95$ ), (2) Measure (eigenvalue $=$ 1.69 , explained variance $=20.14 \%, \alpha=0.92$ ), (3) Strategy (eigenvalue $=1.17$, explained variance $=16.31 \%, \alpha=$ $0.87)$.

Table 3. Factors analysis of public policy and marketing support level $(n=475)$

\begin{tabular}{lllll}
\hline Public Marketing Project & $\begin{array}{l}\text { Public } \\
\text { Marketing } \\
\text { Project }\end{array}$ & Eigenvalue & $\begin{array}{l}\text { Variance } \\
\%\end{array}$ & $\begin{array}{l}\text { Reliability } \\
\text { Coefficient }\end{array}$ \\
\hline POLICY & & 13.94 & 25.77 & 0.95 \\
\hline
\end{tabular}

3.2 Establishment a Regulatory System: including food safety supervision, 0.83 crowd safety norms, local traffic and route specification/ control, immigration arrangements, catering business license, refuse disposal ect.

3.1 Optimize Tourism Environment: including optimize regime and political 0.82 environment, software and hardware environment, ecological and human environment, travel and living conditions ect.

3.3 Expand the Market: primarily endeavor diversity sources market 0.59

\begin{tabular}{|c|c|c|c|c|}
\hline MEASURES & & 1.69 & 20.14 & 0.92 \\
\hline $\begin{array}{l}3.14 \text { Industry should attach importance to service quality upgrade, put 'customer } \\
\text { retention' as a corporate marketing center concept }\end{array}$ & 0.78 & & & \\
\hline $\begin{array}{l}\text { 3.11 Supervise Macao tourism public marketing behavior of each unit as } \\
\text { community, help remain the market order, and benefits consumers from healthy } \\
\text { competition. }\end{array}$ & 0.77 & & & \\
\hline $\begin{array}{l}3.9 \text { Implement public welfare activities, carnival activities into culinary tourism } \\
\text { activities, get residents and tourists participate in. }\end{array}$ & 0.71 & & & \\
\hline $\begin{array}{l}3.10 \text { Establish a good communication channel for tourists and residents by civil } \\
\text { society }\end{array}$ & 0.69 & & & \\
\hline
\end{tabular}




\begin{tabular}{|c|c|c|c|c|}
\hline Public Marketing Project & $\begin{array}{l}\text { Public } \\
\text { Marketing } \\
\text { Project }\end{array}$ & Eigenvalue & $\begin{array}{l}\text { Variance } \\
\%\end{array}$ & $\begin{array}{l}\text { Reliability } \\
\text { Coefficient }\end{array}$ \\
\hline $\begin{array}{l}3.13 \text { Industry should accumulate more cooperation experience, improve } \\
\text { marketing skills and build tourism service chain. Such as united travel agency, } \\
\text { catering supplier cooperation, and shopping-accommodation integration services } \\
\text { ect. }\end{array}$ & 0.68 & & & \\
\hline $\begin{array}{l}3.12 \text { Social group collect information and report to government and tourism } \\
\text { enterprises, working with government and tourism enterprises to solve series of } \\
\text { problems occurring in a tourism activities. }\end{array}$ & 0.58 & & & \\
\hline $\begin{array}{l}\text { 3.8 Provide various public products and services to satisfy targeting consumer's } \\
\text { needs }\end{array}$ & 0.57 & & & \\
\hline $\begin{array}{l}\text { 3.7 Protect natural resources and cultural heritage, improve the sustainable } \\
\text { development of society and maintain a balance in development. }\end{array}$ & 0.56 & & & \\
\hline $\begin{array}{l}\text { 3.15 Establish tourists information system to collecting comments and } \\
\text { satisfaction evaluation. Communication within industry and carry out } \\
\text { improvement plan. }\end{array}$ & 0.56 & & & \\
\hline STRATEGY & & 1.17 & 16.31 & 0.87 \\
\hline $\begin{array}{l}\text { 3.5 Culture Marketing: widely advertise and promote Macao Culinary Tourism } \\
\text { destination though cultural carriers like books, entertainments, theatrics ect. }\end{array}$ & 0.70 & & & \\
\hline $\begin{array}{l}\text { 3.6 Festival Even Marketing: to attract tourists by organize festival and } \\
\text { exhibition, such as Food Festival, Chinese and Foreign Food Tour ect. }\end{array}$ & 0.63 & & & \\
\hline $\begin{array}{l}\text { 3.4 Political Marketing: Macao government sign a cooperation agreement with } \\
\text { the governments of tourists resources to establish cooperation relationship: } \\
\text { Political leaders to visit the target market, launch public relationship activities, } \\
\text { promote Macao Culinary Tourism, develop potential market ect. }\end{array}$ & 0.62 & & & \\
\hline Total variance explained & & & 62.22 & \\
\hline
\end{tabular}

The common factor to explain the maximum total variance percentage (25.77\%) is 'policy'. This factor including three items: Establishment of a Regulatory System, Optimize Tourism Environment and Extend the Market (See Table 3). This factor represents tourists how to evaluate the nature of whether they will support culinary tourism public marketing when they are in the culinary tourism. The items included in the factor is the core of Culinary Tourism public marketing, which is the policy of culinary tourism public marketing.

The second common factor 'Measures' explained $20.14 \%$ total variance, which including 9 measures in government organizations, social groups and tourism industry three scopes. Three measures of the government organizations should do are: Organize Charity Activities, Provide Public Products and Services and Protect Natural Resources and Cultural Heritage; Three measures to be done by social groups are: Supervise main part of marketing, Help solve the problem of tourists and Establish communication channels; Tourism industry should focus on three measures which are: Pay attention to enhance the service quality, Provide integration services and Establish tourists information system. Supporting facilities are very important, not only in boost the value of the core policies, but also in enhance the competitive advantages of tourism destinations.

The third common factor 'Strategy' explained $16.31 \%$ total variance, which including 3 programs: Political Marketing, Culture Marketing and Festival Events Marketing.

There were significant positive correlation between the three variables in the research of correlation matrix $(\mathrm{p}<0.001)$, the correlation coefficient between 0.586-0.782, less than 0.800. Among the three predictor variables and the criterion variable "overall satisfaction" showed a significant positive correlation $(\mathrm{P}<0.001)$, the 
correlation coefficient between $0.626-0.678$ which indicates that the three predictor variables are moderately correlated with the effect variables.

Table 4 is Regression Model Summary Table. From the table can see that three predictor variables and the multiple correlation coefficient of overall satisfaction is 0.762 , coefficient of determination $\left(R^{2}\right)$ is 0.580 , adjusted $\mathrm{R}^{2}$ is 0.578 . Estimated standard error of regression models and (MSE) mean square error is 8.048 . Since it is the only one regression model, which used of force to enter the variable method, the change of $\mathrm{R}^{2}$ is equal to $\mathrm{R}^{2}$ statistical quantity 0.580 , which represents a total of three predictor variables interpreted "overall satisfaction" criterion variable variance of $58 \%$.

In residuals statistics, the minimization of the residual value is -27.214 , maximize residual value is 30.197 , converted to a standardized residuals, the minimum standardized residual value is -3.382 and the maximum standardized residual value is 3.752. From the histogram segment of regression standardized residuals, sample observation value is substantially in line with the normality assumptions, standardized regression residuals within three standard deviations majority, no extreme values appear. From the normal probability distribution of sample standardized residuals opinion, the cumulative probability point of standardized residuals generally distributed near the straight 45 -degree angle, so that the sample of observed values is very close to an assumption of normal distribution.

Meanwhile, to test sample observation value is in accordance with the normality assumption and test residual difference is consistent with the variance homogeneity assumption, through observed the scatter diagram features, scatter plot point randomly distributed in the upper and lower horizontal 0 value, and thus sample observation value consistent with normality and homogeneity of variance assumption.

This research integrates the interpretation based regression analysis above output report to Table 4 as following:

Table 4. Public marketing \& policies, measures and strategies for overall satisfaction of multiple regression analysis summary table

\begin{tabular}{|c|c|c|c|c|}
\hline Predictor Variable & B & Standard Error & Beta $(\beta)$ & t Value \\
\hline Nodal Increment & 14.612 & 1.453 & & 10.056 \\
\hline Policy & .955 & .144 & .210 & $6.625 * * *$ \\
\hline Measure & .403 & .076 & .179 & $5.323 * * *$ \\
\hline Strategy & .596 & .128 & .148 & $4.646 * * *$ \\
\hline
\end{tabular}

$\mathrm{R}=.762 \mathrm{R}^{2}=.580$ adjusted $\mathrm{R}^{2}=.578 \mathrm{~F}=235.344 * * *$

Note. $* * * \mathrm{p}<0.001$.

From Multiple Regression Analysis Summary Table above can discover that, public marketing 'Policy', 'Measure', 'Strategy' three independent variables and "overall satisfaction" criterion variable multiple correlation coefficient is 0.762 , squared multiple correlation coefficient is 0.580 , which indicating a total of three words can explain the variable "overall satisfaction" variable $58 \%$ of the variance. Standardized regression coefficients of the three independent variables are positive, shows the effect of three independent variables on the "overall satisfaction" criterion variables are positive. In the regression model, the public marketing 'Policy', 'Measure', 'Strategy' had a significant effect on criterion variables.

Beta coefficient of the public marketing 'Policy' is 0.21 , which expressed support rating for policy increasing each additional point, the overall satisfaction increased by $0.21(\mathrm{t}=6.625, \mathrm{p}<0.001)$.

Beta coefficient of the public marketing 'Measure' is 0.179 , which expressed support rating for policy increasing each additional point, the overall satisfaction increased by $0.179(\mathrm{t}=5.323, \mathrm{p}<0.001)$.

Beta coefficient of the public marketing 'Strategy' is 0.148 , which expressed support rating for policy increasing each additional point, the overall satisfaction increased by $0.148(\mathrm{t}=4.464, \mathrm{p}<0.001)$. 


\section{Public Policy \& Marketing Design}

\subsection{The Necessity of the Implementation of Macao Culinary Tourism Public Marketing}

Culinary Tourism as a kind of niche market tourism with the characteristics of public products, the government and other public organizations to implement public marketing could better guide and promote its development. Provide culinary tourism products and services of the private organizations are mutual discrete, they sale a single, specific products. Therefore, in the process of destination tourism marketing requires a lot of coordination work and needs the government's intervention and organization. The involvement of government public marketing is conducive to the construction of a large number of public welfare image and organized activities, and to optimize the overall tourism destination image of Macao. To achieve sustainable development of Macao's tourism industry is a long-term public interest behavior, it must be shared with all the people participate in government-led decision making and implementation. In the culinary tourism development process, there are a large number of food safety, health surveillance, quality control and other issues which cannot rely on industry self-regulation, must come forward by the government and public organizations in order to be properly addressed. Relying on the government to implement public marketing policies on culinary tourism could enhance the overall image of the tourism destination, and forming a competitive tourism characteristics, thereby enhancing the diversification of Macao's tourism industry.

\subsection{Macao Culinary Tourism Marketing Policy Recommendations}

1) Tourism Environment Optimization: Including the optimization of the institutional and policy environment, software and hardware environment, ecology and human environment, tourism and residential environment, etc.

2) Establishment Of The Regulatory System: Including food hygiene and safety supervision, crowd safety standards, local traffic and route standard / control, immigration arrangements, catering business license, garbage disposal, etc..

3) Market Development: Mainly vigorously expand diversified tourist market, thereby reducing the risk of Macao single gaming tourist industry type, promote tourism diversification and enhance the international competitiveness of the tourist destinations.

4) The Overall Target Market Positioning Strategy Formulation: Including from a overall tourist area to investigate the culinary tourists' motivation, discover the needs of tourists, and engaged in related research, etc.

5) Policy Advice and Opinion Polls: To eliminate doubts, the development of culinary tourism should be transparent and open for residents.

6) Policy Transparency and Accountability Establish: Transparency and accountability are the bases of sustainable development, which including anything relative culinary sustainable development and they are also the basic requirement of community involvement and sharing of benefits resulting sustainable economic benefits. In the government process of the development culinary tourism, publish comprehensive and detailed information for public awareness and strengthen public oversight authority to use public funds to prevent the indiscriminate use of public funds phenomenon.

7) Culinary Tourism Brand and Image Building: Including the use of various forms of public marketing communication channel and will be consistent with the Macao Culinary Tourism destination image information to the target customers and other important relationships to achieve two-way interactive communication, thus establishing the brand image of Macao leisure tourism destination.

8) Regional Cooperation In Tourism: Including have a comprehensive understanding the target market consumers and regional competitors, and then to seek the advantages from the differences and to seek cooperation in the competition, in cooperation continuously upgrade their own advantages.

9) The Importance of Community Participation: Public funds into the development of culinary tourism could not only bring benefits to a few people, it should provide more employment opportunities and participation platform. So that a considerable number of local residents to participate directly in the decision-making process, and to share achieved benefits. Reduce the contradiction and conflict between the community residents' welfare and tourism benefits.

10) The Utilization and Protection Of Macao Culinary Cultural Resources: Using tourism to promote Macao heritage culinary ressources and protect and inherit intangible heritage. While absorbing and drawing on foreign culinary tourism culture development mode, formulating the policy of Macao development of intangible cultural tourism products and protection of the area intangible cultural heritage. Strengthen the arrangement, protection, exploit and development of catering and cultural heritage in Macao intangible cultural heritage, accordingly to 
enrich Macao existing tourism products and promote sustainable development of tourism, and better protection of intangible heritage, inheritance and development.

11) Macao Catering Industry "Risk Management": Establish a "risk management" concept and establish a strict food safety management system in order to make Macao colorful catering culture to seize market opportunities, explore cultural characteristics and play their strengths. An important breakthrough to expand the influence of the Macao Culinary Tourism is correct operation positioning, and it will also an important foundation to seek more development opportunities of Macao catering industry.

\subsection{Macao Culinary Tourism Public Marketing Strategy}

1) Political Marketing, the Macao SAR government signed a cooperation agreement with the governments of tourists sources to establish a cooperative relationship; Political leaders visit the target market and carry out public relations activities to promote the Macao Culinary Tourism and expand the potential market a series of government marketing activities.

2) Culture marketing that is through books, film and television entertainment, theater performances and other cultural carriers, widespread publicity to promotion Macao Culinary Tourism destination. Especially the use of voice, graphic and text of TV media influence to promote the formation of fashion consumption, such as CCTV documentary "A Bite of China" play the key role to attract multinational citizen travel to China.

3) Festival Event Marketing, through organize festival even activities, for example food festival carnival, foreign food tour to attract tourists and could add recreational activities for local residents.

4) Social Marketing through the regional internal marketing to obtain the support of local residents in Macao, and actively guide them to participate in regional food tourism marketing activities. Give full play to their role as the host and stakeholders to promote the rapid and healthy development of Macao tourism.

5) Celebrity Promotion, mainly refers to a variety of socially influential people use their social status and role model to influence some of the potential tourist market. Such as selecting the celebrity as a tourist destination ambassador to promote the entire product of Macao Tourism.

6) Buzz Marketing, which is stimulate the tourists by word of mouth, their intuitive feelings and experience of Macao food tourism destination information will be spread out and form a reputation effect. Here also note that the virtualization features of word of mouth spread in the era of network marketing, the government should seriously study the communicability and other characteristics of public marketing. It played a significant role of the brand image in a tourist destination. In the past cognitive form of buzz marketing, mainly among people who know each other by word of mouth, but in the network world, word of mouth is spread by strangers to each other. It is invisible, elusive and has obvious virtualization features, therefore, it can easily be overlooked. However, due to the unique scalability of the network, information dissemination can effectively break through time and space constraints, and instantly reach all aspects and corner of social life. For the more important image of tourist destination, how to form a good "virtual word of mouth" in the network world is a problem worthy of study.

7) New Media Marketing, as a new fourth media, online marketing is different from traditional marketing is simply interaction and cross-temporal characteristics of the network, as well as consumer demand for personalized return. For the tourism industry, the emergence of the Internet is a great boon, the network provides a rich and convenient information for tourists and also provides a rich variety of display methods and channels for tourism industry.

\subsection{Specific Measures for the Development of Macao Culinary Tourism}

This research discussed the work in the culinary tourism should be undertaken by three aspects which are government departments, tourism industry, and civil society:

\subsubsection{Work by Government Departments}

1) Provide a variety of public products and services that meet the social needs of the target customers.

2) Sponsor and support for the construction of the basic facilities, to provide convenient for the residents living and to improve the quality of life in Macao, make the city leisure and livable.

3) Coordinate and resolve the group conflict, establish a harmonious management order, provide high quality tourism experience for the tourists.

4) Put the public welfare activities, carnival activities into culinary tourism activities, so that residents and visitors can participate in. 
5) Protect natural resources and cultural heritage, to promote sustainable development of society, maintain a fair in development.

6) Tourism information policy formulation and management. Legislation laws and regulations of management, the introduction of tourism information technology related management regulations, which including website domain name, website name, content, business scope, dissemination, filing, the official website must implement the norms of information exchange standards and information sharing, etc. It should also include information systems planning, feasibility studies, construction, audit, inspection, etc. Develop appropriate management practices for building Public Services Centre: the scope and duties in tourist information and other information centers to be confirmed and standardized.

\subsubsection{Work by Tourism Industry}

1) Emphasis on service quality improvement, the "customer retention" as the center of enterprise marketing idea.

2) More experience in the accumulation of industry cooperation, improve marketing skills, establishment of tourism service chain, such as travel agencies combined, catering providers coordinated, accommodation and shopping integrated services, etc...

3) Establishment of tourist information system to collect tourists comments and evaluate customer satisfaction, communicating within industry, so that reform program.

\subsubsection{Work by Civil Society Groups}

1) Play the role of social public benefit of civil society groups, strengthen the function of the link between the government and community residents and tourists.

2) Gather industry information, reflect to the government and tourism enterprises, working with the Government and tourism enterprises to solve a series of problems in tourism activities.

3) Supervise the marketing behavior of the main bodies of Macao tourism public marketing, and maintain the market order; coordinate the conflicts of interests among the tourism enterprises, and resolve the conflicts.

4) Training of tourism enterprises and community residents. Generally speaking, tourism-related industry is a labor-intensive service industries, which the tourism industry practitioners is an important part of the overall experience of tourists. The reputation of the tourism products is a great proportion based on the service staff and customer interaction process which brought to the customer's experience. While providing high-quality tourism products and services depends on a high-quality tourism manpower. Recommendations for future tourism development strategy of human capital should not be limited in Macao quality tourism manpower training, but should pay attention to the power of civil society, training of frontline service personnel and support for Macao local medium and small enterprises.

\section{References}

Giliberto, C. (2013). Policy Design: Principles and Process, Policy Design, International Conference on Public Policy. Retrieved from http://www.icpublicpolicy.org/Policy-Design-Principles-and\#

Jang, D., \& Mattila, A. (2005). An Examination of Restaurant Loyalty Programs: What Kind of Rewards do Customers Prefer? International Journal of Contemporary Hospitality Management, 17(5), 65-248.

Meg, H. (2008). Wine connoisseurs or curious tourists? The participants in wine festivals. Food and wine festivals and events around the world (1st ed.). Chichester: Butterworth-Heinemann, 179-180.

Read, S. E. (1980). A prime force in the expansion of tourism in the next decade: special interest travel. In D. E. Hawkins, E. L. Shafer, \& J. M. Rovelstad (Eds.), Tourism Marketing and Management Issues. Washington D.C.: George Washington University.

Saleh, F., \& Ryan, C. (1993). Jazz and Knitwear : Factors that Attract Tourists to Festivals. Tourism Management, 14(4), 289-97. http://dx.doi.org/10.1016/0261-5177(93)90063-Q

Sylvia, S., \& Carol, C. (2008). Culinary tourism: Satisfaction with a culinary event utilizing importance-performance grid analysis. Journal of Vacation Marketing, 15(2), 99-110. 


\section{Copyrights}

Copyright for this article is retained by the author(s), with first publication rights granted to the journal.

This is an open-access article distributed under the terms and conditions of the Creative Commons Attribution license (http://creativecommons.org/licenses/by/3.0/). 